\title{
Research Review on Equity in Basic Medical Insurance
}

\author{
Qilin Deng \\ School of Public Administration and Emergency Management, Jinan University, Guangzhou, China \\ Email: dengqilin818@163.com
}

How to cite this paper: Deng, Q.L. (2019) Research Review on Equity in Basic Medical Insurance. Open Journal of Social Sciences, 7, 379-389.

https://doi.org/10.4236/jss.2019.74030

Received: April 2, 2019

Accepted: April 26, 2019

Published: April 29, 2019

Copyright $\odot 2019$ by author(s) and Scientific Research Publishing Inc. This work is licensed under the Creative Commons Attribution International License (CC BY 4.0).

http://creativecommons.org/licenses/by/4.0/

\section{c) (i) Open Access}

\begin{abstract}
This study focuses on the equity of basic medical insurance. Through reviewing a large number of relevant literatures, the theoretical sources, measurement methods and empirical research on equity in basic medical insurance are summarized. The study found that scholars currently conduct research on the equity of basic medical insurance mainly from the two theories of welfare economics and social justice theory. Scholars generally use the concentration index, the level index, and the regression method to measure the equity of basic medical insurance. Many empirical studies have shown that basic medical insurance improves the level of health care and health on the one hand, but on the other hand it widens the fair gap between the insured and the non-insured. This paper concluded that the current equity of basic medical insurance still has certain limitations, and future research can progress toward related research. I hope this study can provide a reference for improving health and equity.
\end{abstract}

\section{Keywords}

Basic Medical Insurance, Equity and Efficiency, The Level of Health Care and Health, Utilization of Health Resources

\section{Introduction}

The World Health Organization (WHO) put Health Equity as the subject of the report in the 2000 World Health Report and defined health equity as: whether it is defined by social, economic, demographic, geographic, etc. there is no health gap between them. Since then, scholars from various countries have begun to pay attention to the fairness of the Health Care system or the Medical Insurance system.

In order to effectively alleviate the problems of expensive medical treatment 
and to promote people's fair access to medical and health services, the Chinese government has made tremendous efforts and has successively introduced a number of policy measures to continuously improve the basic medical security system. As of 2017, China's basic medical insurance coverage exceeded 1.3 billion people, almost universal health insurance. In China, one of the important institutional goals of the basic medical insurance system is to achieve health equity. Under the influence of basic medical insurance, the enthusiasm of people for medical treatment has been significantly improved, the level of medical and health services has improved, and the use of medical self-pay has also declined [1].

The implementation of the basic medical insurance system will benefit more vulnerable groups and guarantee their right to health. However, in China, the types of basic medical insurance that different groups participate in are different, and the treatment they enjoy is different. Is this difference caused by institutional differences reasonable? Will it result in unfair treatment or unhealthy? This article will focus on the issue of equity of basic medical insurance. On the basis of literature research, this paper summarizes the theoretical sources, measurement methods and influencing factors of China's basic medical insurance equity, and then, the author summarizes the current research situation of scholars on the equity of basic medical insurance, and proposes possible follow-up research directions to provide reference for the improvement of China's basic medical insurance. The rest of the paper is organized as follows: firstly, the theoretical source of the fairness of basic medical insurance, the second part introduces the current research on the equity of basic medical insurance, and the third part is the author's review of relevant research.

\section{The Theoretical Source of Equity in Basic Medical Insurance}

Like most countries' health protection systems, the institutional goals of China's basic medical insurance system are not only social equity, but also the optimal allocation of social medical service resources. Based on this, the academic source of the fairness of the basic medical insurance system generally comes from two aspects. Part of this is the theory of welfare economics based on the optimization of resource allocation, and others are the theory of social justice based on the principle of priority of the weak. These two theories are classic theories of social security issues, and they have a strong explanatory role in studying the equity of basic medical insurance. Scholars usually start from these two theories, study the issue of equity in basic medical insurance, and obtain the basis for the fair value selection of basic medical insurance from the theory.

From the theoretical perspective of resource allocation optimization, scholars believe that the basic medical insurance system should balance the relationship between distribution efficiency and distribution justice. More scholars tend to support the distributional efficiency over distribution justice. For example, Douthit N (2015) believes that the US health insurance system flexibly uses the power of the market [2]. The government, enterprises and employees share the 
medical insurance contributions. The private sector is responsible for operating the insurance fund, so the efficiency is high and the government has no financial burden. On the other hand, the UK's National Health Service (NHS) reflects the drawbacks of neglecting the efficiency of distribution. The highly inclusive health care benefits, while reflecting the distributional justice, bring a heavy financial burden and low health system efficiency [3]. Although the welfare economic theory advocates the optimization of resource allocation, there is no clear standard for the definition of "optimal". In general, if we ignore the issue of equity in order not to increase the financial burden of the government, it will cause social instability.

In addition, many scholars use Rawls' social justice theory to demonstrate the equity of the health protection system or the medical security system based on the perspective of "weak priority". Wagstaff (2000) believes that the socially disadvantaged groups should be the focus of government social insurance, and the government should do its utmost to protect the health rights of these social bottoms [4]. In practice, many countries and regions have incorporated the principle of "weak priority" into specific medical insurance opportunities. For example, in Taiwan, the income of lower-income groups from insurance is higher than that of higher-income groups [5], which played a certain role in narrowing the gap between rich and poor.

Whether it is focusing on resource allocation optimization or tending to protect vulnerable groups, the ultimate discussion is the relationship between efficiency and equity. How to balance the relationship between efficiency and fairness has become an important link in the construction of national institutional systems. The development of China's basic medical insurance system has gone through many stages, and the issue of equity in the basic medical insurance system has become a hot topic in academic circles.

\section{Advances in Empirical Research on Fairness in Basic Medical Insurance}

\subsection{The Connotation of the Equity in Basic Medical Insurance}

Before conducting the study of equity in the basic medical insurance system, scholars will define the meaning of "equity". Equity is a different concept than Equality. Equality represents the undifferentiated equivalence, and fairness represents the choice of discriminatory treatment.

Equity is a concept related to value orientation and value choice, which is difficult to define. In Whitehead's 1992 article, his defined the equity of health care as: equal access to available care for equal need; equal use to meet equal needs; equal quality of care for all [6]. Whitehead's definition of health care equity encompasses three aspects. First, equal access to health care for the same needs means that the same care needs should be obtained between groups and groups, because they have equal opportunities for health care; Secondly, equal use to meet the need for equality, that is, the equal use of health care services, is a 
process fair; Third, everyone who enjoys the same quality of health care emphasizes fair results. Based on the definition of equity in health care, some scholars began to analyze the equity of China's basic medical insurance system. China's basic medical insurance system was originally established to solve problems such as "difficulty in seeing a doctor" and "expensive medical treatment". The purpose is to promote fair access to medical and health services. The equity of the basic medical insurance system is mainly reflected in the coverage and medical or health services. The coverage of the basic medical insurance system has been greatly improved after the new medical reform, which means that most people have equal access to health care opportunities and equity in opportunities are realized [7]. In terms of the level of medical or health services, including the accessibility of medical resources, the utilization level of medical and health services, and the proportion of reimbursement for medical expenses, China's medical or health resources are significantly different between urban and rural areas [8]. There are also differences in the number of medical services and reimbursement rates for different types of basic medical insurance [9]. How to ensure that these differences are kept within reasonable limits and that the level of health care services is fair is further explored.

\subsection{Medical Resource Allocation and Equity}

One of the important contents of the health care system is the rational allocation of medical and health resources, and the efficiency of the health care system has been improved through the optimal combination of medical and health resources. The fair distribution of medical resources is the goal of the modern medical security system. Whether it is a medical unfair comparison within the country or globally, it is ultimately more specific to study the relationship between medical resource allocation and the equity of medical service utilization.

The allocation of health care resources affects the fair use of health care services. That is to say, the accessibility of health care resources may reflect the fairness of the health insurance system than the availability [10].

Meng Q et al. (2012) analyzed the data of China's 2003-2011 NHSS survey and found that there is an obvious inequity distribution of medical and health resources in China [1]. This kind of inequity is not only reflected in the quantity of medical and health resources, but also in the quality of medical and health resources. The city has more medical resources than the rural areas and better quality. The developed eastern regions are richer in health care resources than the less developed regions of the central and western regions. Although China's rapid urbanization has led to a large number of people moving from rural to urban areas, these rural immigrants are usually not eligible to participate in urban health insurance plans. For rural-to-urban immigrants, even if they participate in the New Rural Cooperative Medical Care, it is difficult to obtain compensation for health care in urban areas [11]. In addition, the distribution of urban and rural health care resources is uneven, and will also be affected by the income 
gap. It is reported that the income inequality in health care services is greater than in urban areas in rural areas because of the greater income disparity among rural populations. In rural areas, people with higher incomes are more likely to get out of the countryside to enjoy better health care resources than those with lower incomes because of their higher affordability [12]. Differences in the allocation of health care resources have led to poor access to health care services in underdeveloped and rural areas, which further affects the level of utilization of their health services and may ultimately lead to differences in health performance. The role of basic medical insurance in these links may also be affected.

The unfair use of health care services is often caused by the unfair distribution of social resources, especially medical resources. The negative correlation is reflected in the large differences in the total amount of medical resources between rich countries and poor countries. Moreover, the resulting health outcomes are inequitable [13]. In contrast, health care systems in low- and middle-income countries have many weaknesses, the most obvious of which is inadequate financial protection for specific population groups. The government has taken less fiscal measures to improve the health care utilization and quality of care of these groups [10]. In other words, in these low- and middle-income countries, health care resources are more inclined to groups with higher social status, and the support for vulnerable groups is insufficient. For example, in China, although China has established the world's largest social security net, the problems of low security level and unbalanced resource allocation have become increasingly prominent. As far as urban residents' medical insurance is concerned, Pan J et al. (2016) used the survey data of urban residents' medical insurance households from 2007 to 2011, and estimated the income distribution by using two models to find that the income of low- and middle-income groups is low [14]. In the case of high-income groups, in other words, government subsidies that should promote universal health insurance flow more to the rich. Specifically, Liu X. et al. (2012) found that the level of outpatient utilization was not significantly affected by basic medical insurance through the analysis of household surveys in urban and rural areas in China, while the level of hospitalization utilization was significantly affected by basic medical insurance [15]. China has achieved higher basic health insurance coverage in a short period of time. However, the poor have benefited less from the new rural cooperative medical insurance in terms of health service utilization [16].

The allocation of medical and health resources has a significant impact on the fairness of the utilization of medical and health services. Such conclusions have been received by many scholars, but the impact is positive or negative, and scholars' views are also different. As Levy and Meltzer (2008) concluded, they reviewed the impact of health care insurance on the level of health care services and health [17]. Many studies available internationally do not show the level of health care coverage and health care. However, existing research indicates that social health insurance plans can improve the level of health care utilization and 
health of some population groups, such as the elderly and children, and the key is to evaluate the criteria for these health care plans.

\subsection{Standards and Evaluation of the Equity of Basic Medical Insurance System}

Because of the different understanding of the connotation of medical health protection, scholars also hold different opinions on how to evaluate and measure the equity of the medical insurance system. In fact, a large part of the evaluation of the equity of the medical and health insurance system depends on the institutional goals of these different medical and health insurance systems from the beginning of establishment. Generally speaking, "equal opportunity" is the first principle of medical insurance system, but in fact, when evaluating and measuring the equity of medical health protection, more scholars pay attention to the process of using health care services between individuals or groups at the micro level, such as the fairness of the quantity, quality and cost of medical and health services.

When studying the equity of China's basic medical insurance system, in general, scholars or experts mainly evaluate the equity of the basic medical insurance system from the macro level or the micro level.

1) Macro level

At the macro level, many scholars generally measure the equity of China's basic medical insurance system in terms of institutional coverage, public health status, and allocation efficiency of basic medical insurance resources.

In terms of institutional coverage, Wagstaff et al. (2010) compared the effects of China's "new medical reform" through empirical research and found that the "new medical reform" solved the medical and health system that China faced in the new millennium [18]. The most obvious one is that the emergence of the new rural cooperative medical system not only increased the subsidies for farmers' health care, but also further expanded the coverage of medical insurance, which reduced the coverage of insurance in the vast rural areas of China and urban areas. On the other hand, Ming Q. et al. (2015), through research on China's basic medical insurance system, also found that in order to expand the coverage of the basic medical insurance system, China has adopted a different basic medical insurance system type for different groups [19]. Therefore, a fragmented medical insurance system has been formed, which has brought about low utilization efficiency of medical and health services. This fragmented basic medical insurance system is an important factor in the unfair proportion of people's health care in China.

In terms of public health, scholars generally use the Concentration Index, the Horizon Inequity Index, or the regression method to measure differences in health status between countries, between regions, and between individuals [7] [20].

In terms of the efficiency of basic medical insurance resource allocation, Gong Y. et al. (2018) found that the quality of community health services was significantly improved by using the 2008 and 2011 Chinese community survey data to compare the variables of community medical service quality before and after the 
new medical reform [21]. After the health care reform, community health hospitals have further improved the average floor area, quantity and equipment. In addition, Zhou X. et al. (2011) used the panel data from 1991 to 2007 in 30 provinces of China as samples to perform local linear estimation of the data [22]. The results show that in China, rural and urban health care and medical services are highly flexible; in addition, the share of health care and medical services in the total consumption expenditure varies widely between urban and rural areas, mainly due to urban and rural basic medical insurance. The difference in reimbursement ratio is large. Si L. et al. (2016) conducted a benefit-related analysis of government medical subsidy data (GHS) in the 2003 and 2008 China Health Service Surveys [8]. The results showed that the fairness of government subsidies in outpatient medical services improved. However, there is no such thing as hospital health services, and high-income people are the main beneficiaries of government medical subsidies.

2) Micro level

At the micro level, scholars focus on the differences in the level of utilization of health services between individuals and the differences in health levels, and explore the relationship between these differences and the basic medical insurance system.

In the level of utilization of health care services, "utilization of health care services" generally refers to the number of medical services and the cost of medical services in related research in the West [23]. In China, "health services" mainly include the two aspects of outpatient services and inpatient services, and "health utilization" is generally operated as the frequency of outpatient services and inpatient services and the cost of outpatient and inpatient services.

In terms of the utilization level of medical and health services, ZHOU Z L et al. (2014) used the propensity score matching method (PSM) to conduct empirical research on the survey data of Shaanxi Province, China [9]. The study found that the medical insurance system is an important factor affecting people's use of health care services. The inequality index of outpatient and inpatient services for residents with and without medical insurance is more than $10 \%$. Cai J. et al. (2017) used the CHNS data from 1991 to 2006 to use socioeconomic status as a control variable, and analyzed that medical insurance has improved people's outpatient and hospitalization rates [24]. Specifically, urban workers' medical insurance is most significant. It can be seen that medical insurance increases the utilization rate of medical services for those who have medical insurance, and on the other hand, it further expands the medical care between medical insured and non-medical insured or between different medical insurers user. On the other hand, although the continuous improvement of the medical insurance system has increased the proportion of reimbursement for medical expenses, it has also created new unfair issues. Si L et al. (2016) conducted a fair analysis of the proportion of China's urban and rural medical insurance reimbursement [8]. The study found that medical insurance is conducive to improving the fairness of outpatient medical services between urban and rural areas, but it does not im- 
prove the difference in the cost of hospitalization services between urban and rural areas. The high-income group in cities is the beneficiary of medical insurance. Although health insurance can improve people's health care service use, the effect varies from person to family and from the health insurance system [25]. There is an inequality in the probability and frequency of people using health services, and this inequity is clearly beneficial to the rich [26]. Basic medical insurance solves some of the burden of medical expenses for patients, but this proportion is relatively low. In the face of serious illness, family economic status and personal socioeconomic status play an important role in the use of medical and health services.

At the health level, scholars generally divide the "health status" into two aspects: subjective health status and objective health status. In terms of objective health, in general, after controlling for variables of personal characteristics, regions, and socioeconomic status, people with basic medical insurance have a lower chance of developing chronic diseases than those without basic medical insurance. One possible explanation is that people with basic health insurance have higher health care and better prevention of chronic diseases [27]. Yin H. et al. (2017) conducted a study on the factors affecting Chinese women with chronic diseases by using the 2008 China National Health Service Survey data [28]. The results show that socioeconomic status factors are related to the increased risk of non-communicable diseases among Chinese women. Social economic status factors play a key intermediary role in the correlation between non-communicable diseases. In terms of mental health, Song L. et al. (2015) used data from the US and China surveys in 2004 to analyze the impact of socioeconomic status on health and to explain the health effects of reference groups [29]. The main dependent variables show that the comparative reference group theory is more applicable to the United States, and the socioeconomic status determinism is more applicable to China. Specifically, in China, adults who believe that their income is lower than the income of social interactions are less physically and mentally healthy, while the opposite adults are healthier and basic medical insurance has little effect. In addition, Paolucci et al. (2014) analyzed the policy preferences of Chinese health policy makers, and found that respondents strongly prefer efficiency standards, rather than fairness standards [30], that is, to consider overall health beneficiaries and cost-effectiveness. Reflected in health outcomes, groups with higher levels of health insurance have better health outcomes.

\section{Review of Equity Research in Basic Medical Insurance}

Scholars have not yet formed a unified view on the definition of equity in basic medical insurance system. Jia Kang, vice president of the Chinese Finance Association, has defined the "equity" in basic medical insurance. He believes that "the starting point fairness" and "process fairness" mean "Fairness" in English, and "the result is fair" means equity. In many foreign literatures, scholars often use "Equity" to express the meaning of fairness. It can be seen that in the foreign li- 
terature on the fairness of China's basic medical insurance, most of the "fairness" point to "fairness of results."

However, scholars have not yet formed a unified statement on the criteria for evaluating the fairness of the basic medical insurance system. Some scholars tend to measure the fairness of the basic medical insurance system from a macro perspective, using the allocation of medical and health resources, the public health status, and the financing system of the basic medical insurance system. However, this method of measurement is easy to ignore the basic medical insurance evaluation of the protection of vulnerable groups. Another part of the scholars tends to measure the equity of the basic medical insurance system from a micro perspective. This part of the study usually separates the level of medical service utilization from the level of health for research. There is also a complex relationship between the use of medical services and the level of health. On the one hand, higher levels of health care can promote health, and on the other hand, groups with weaker health may use health care services more frequently. Therefore, when measuring the fairness of the basic medical insurance system from a microscopic point of view, the level of utilization of health care services should be combined with the level of health, and the interaction between the two should be considered. In addition, some scholars measure the fairness of basic medical insurance from the perspective of "cost-benefit", but this method also has limitations. Because health care behavior is not a simple economic behavior, it cannot be simply considered in people's lives and health care. If you have the ability to meet the income and expenditure, you need to consider the support capabilities of the basic medical insurance system.

In China, the implementation of basic medical insurance enables people to enjoy medical and health services at a lower cost, and to a certain extent avoids the phenomenon that people can delay treatment because they cannot afford the cost of medical services. This not only improves the level of people's use of health care services, but also promotes health equity to a certain extent. However, the impact of different basic health insurance on health care utilization and health outcomes is different. Specifically, the effect of higher-level basic medical insurance on reducing health inequities is more obvious. Therefore, in order to thoroughly study the fairness of basic medical insurance, the key factor of basic medical insurance type must be considered. The issue of fairness in the basic medical insurance system is related to people's specific well-being and social stability, but the method of measuring its fairness has not yet been formed, and there is still much room for research.

\section{Conflicts of Interest}

The author declares no conflicts of interest regarding the publication of this paper.

\section{References}

[1] Meng, Q., Xu, L., Zhang, Y., et al. (2012) Trends in Access to Health Services and Financial Protection in China between 2003 and 2011: A Cross-Sectional Study. The 
Lancet (British Edition), 379, 805-814. https://doi.org/10.1016/S0140-6736(12)60278-5

[2] Douthit, N., Kiv, S., Dwolatzky, T. and Biswas, S. (2015) Exposing Some Important Barriers to Health Care Access in the Rural USA. Public Health, 129, 611-620. https://doi.org/10.1016/j.puhe.2015.04.001

[3] Wenzl, M., Mccuskee, S. and Mossialos, E. (2015) Commissioning for Equity in the NHS: Rhetoric and Practice. British Medical Bulletin, 115, 5-17. https://doi.org/10.1093/bmb/ldv031

[4] Wagstaff, A. (2000) Research on Equity, Poverty and Health Outcomes: Lessons for the Developing World. World Bank, Washington DC.

[5] Huang, N., Yip, W., Chou, Y.-J. and Wang, P.-J. (2007) The Distribution of Net Benefits under the National Health Insurance Programme in Taiwan. Health Policy and Planning, 22, 49-59. https://doi.org/10.1093/heapol/czl037

[6] Whitehead, M. (1992) The Concepts and Principles of Equity and Health. International Journal of Health Services, 22, 429-445.

https://doi.org/10.2190/986L-LHQ6-2VTE-YRRN

[7] Wu, J., Liu, J., Zhu, B. and Mao, Y. (2015) Does China's New Medical Reform Improve Health Equity of Rural Residents? Evidence from Household Surveys before and after the Implementation of New Medical Reform in Shaanxi Province, China. Value in Health, 18, A526. https://doi.org/10.1016/j.jval.2015.09.1623

[8] Si, L., Chen, M. and Palmer, A.J. (2017) Has Equity in Government Subsidy on Healthcare Improved in China? Evidence from the China's National Health Services Survey. International Journal for Equity in Health, 16, 6. https://doi.org/10.1186/s12939-017-0516-Z

[9] Zhou, Z.-L., Zhu, L., Zhou, Z.-Y., et al. (2014) The Effects of China's Urban Basic Medical Insurance Schemes on the Equity of Health Service Utilisation: Evidence from Shaanxi Province. International Journal for Equity in Health, 13, 23. https://doi.org/10.1186/1475-9276-13-23

[10] Mills, A. (2014) Health Care Systems in Low- and Middle-Income Countries. The New England Journal of Medicine, 370, 552-557. https://doi.org/10.1056/NEJMra1110897

[11] Meng, Q. and Xu, K. (2014) Progress and Challenges of the Rural Cooperative Medical Scheme in China. Bulletin of the World Health Organization, 92, 447-451. https://doi.org/10.2471/BLT.13.131532

[12] Xie, E. (2009) Income-Related Inequality of Health and Health Care Utilization. Frontiers of Economics in China, 6, 131-156. https://doi.org/10.1007/s11459-011-0125-5

[13] Howse, K. (2012) Editorial: Health Inequalities and Social Justice. Journal of Population Ageing, 5, 1-5. https://doi.org/10.1007/s12062-012-9058-8

[14] Pan, J., Tian, S., Zhou, Q. and Han, W. (2016) Benefit Distribution of Social Health Insurance: Evidence from China's Urban Resident Basic Medical Insurance. Health Policy and Planning, 31, 853-859. https://doi.org/10.1093/heapol/czv141

[15] Liu, X., Tang, S., Yu, B., et al. (2012) Can Rural Health Insurance Improve Equity in Health Care Utilization? A Comparison between China and Vietnam. International Journal for Equity in Health, 11, 10. https://doi.org/10.1186/1475-9276-11-10

[16] Yan, F., Raven, J., Wang, W., et al. (2012) Management Capacity and Health Insurance: The Case of the New Cooperative Medical Scheme in Six Counties in Rural China. The International Journal of Health Planning \& Management, 26, 357-378. https://doi.org/10.1002/hpm.1028 
[17] Levy, H. and Meltzer, D. (2008) The Impact of Health Insurance on Health. Annual Review of Public Health, 29, 399-409. https://doi.org/10.1146/annurev.publhealth.28.021406.144042

[18] Wagstaff, A., Yip, W., Lindelow, M. and Hsiao, W.C. (2010) China’s Health System and Its Reform: A Review of Recent Studies. Health Economics, 18, S7-S23. https://doi.org/10.1002/hec.1518

[19] Meng, Q., Fang, H., Liu, X., Yuan, B.-B. and Xu, J. (2015) Consolidating the Social Health Insurance Schemes in China: Towards an Equitable and Efficient Health System. The Lancet, 386, 1484-1492. https://doi.org/10.1016/S0140-6736(15)00342-6

[20] Su, M., Zhou, Z., Si, Y., et al. (2018) Comparing the Effects of China's Three Basic Health Insurance Schemes on the Equity of Health-Related Quality of Life: Using the Method of Coarsened Exact Matching. Health and Quality of Life Outcomes, 16, 41. https://doi.org/10.1186/s12955-018-0868-0

[21] Gong, Y., Xu, J., Chen, T., Sun, N., Lu, Z. and Yin, X. (2011) The Effect of the Latest Health Care Reforms on the Quality of Community Health Services in China. The International Journal of Health Planning and Management, 99, e1225-e1231.

[22] Zhou, X. and Tian, F. (2011) A Comparative Study on the Health Care and Medical Service Consumption of Urban and Rural Households in China. Journal of Economic Studies, 38, 17-29. https://doi.org/10.1108/01443581111096123

[23] Diehr, P., Yanez, D., Ash, A.S., Hornbrook, M. and Lin, D.Y. (1999) Methods for Analyzing Health Care Utilization and Costs. Annual Review of Public Health, 20, 125-144. https://doi.org/10.1146/annurev.publhealth.20.1.125

[24] Cai, J., Coyte, P.C. and Zhao, H. (2017) Decomposing the Causes of Socioeconomic-Related Health Inequality among Urban and Rural Populations in China: A New Decomposition Approach. International Journal for Equity in Health, 16, 128. https://doi.org/10.1186/s12939-017-0624-9

[25] Bai, C.-E. and Wu, B. (2014) Health Insurance and Consumption: Evidence from China's New Cooperative Medical Scheme. Journal of Comparative Economics, 42, 450-469. https://doi.org/10.1016/j.jce.2013.07.005

[26] Fu, X.-Z. Nan, S., Fei, X., et al. (2018) Influencing Factors of Inequity in Health Services Utilization among the Elderly in China. International Journal for Equity in Health, 17, 144. https://doi.org/10.1186/s12939-018-0861-6

[27] Miao, J. and Wu, X. (2016) Urbanization, Socioeconomic Status and Health Disparity in China. Health \& Place, 42, 87-95.

https://doi.org/10.1016/j.healthplace.2016.09.008

[28] Yin, H., Wu, Q., Cui, Y., et al. (2017) Socioeconomic Status and Prevalence of Chronic Non-Communicable Diseases in Chinese Women: A Structural Equation Modelling Approach. BMJ Open, 7, e014402.

https://doi.org/10.1136/bmjopen-2016-014402

[29] Song, L. (2015) Does Who You Know in the Positional Hierarchy Protect or Hurt? Social Capital, Comparative Reference Group, and Depression in two Societies. Social Science \& Medicine, 136-137, 117-127. https://doi.org/10.1016/j.socscimed.2015.05.012

[30] Paolucci, F., Mentzakis, E., Defechereux, T. and Niessen, L.W. (2014) Equity and Efficiency Preferences of Health Policy Makers in China-A Stated Preference Analysis. Health Policy \& Planning, 30, 1059-1066.

https://doi.org/10.1093/heapol/czu123 